\title{
ЭКОНОМИЧЕСКАЯ ЭФФЕКТИВНОСТЬ ИПОТЕЧНОГО КРЕДИТА ДЛЯ ПРИОБРЕТЕНИЯ КВАРТИРЫ В НОВОСТРОЙКЕ В МОСКВЕ
}

\author{
(c) 2021 Дубинин Артем Сергеевич \\ бакалавр, студент магистратуры, направление «Финансовый менеджмент и рынок капитала» \\ Финансовый Университет при Правительстве РФ, Россия, Москва \\ E-mail: matan092@yandex.ru
}

В статье представлены результаты проверки гипотезы об эффективности ипотечного кредита для приобретения жилья в новостройке в Москве. Производится расчет, что в конце срока кредита было бы выше, стоимость приобретенного жилья или накопленный капитал с помощью инвестирования в ОФЗ.

Ключевые слова: Ипотечный кредит, эффективность ипотечного кредита, ипотечные кредит или аренда квартиры

Большинство населения, особенно молодого возраста, хочет обзавестись собственным жильем, чтобы или начать полностью самостоятельную жизнь, или же закончить обживать съемное жилье. В умах людей очень прочно засела мысль покупки жилья и построения своего собственного «уютного, надежного и безопасного уголка».

Учитывая, что приобретение собственного жилья - это очень дорогостоящая покупка, заметно большая часть покупателей вынуждена обращаться для этого к ипотечному кредитованию. В связи с чем в настоящее время ипотечное кредитование все более и более сильно становится неотъемлемой частью жизни людей.

Ипотечный кредит - это одна из разновидностей кредита, который выдается на долгий срок, имеет целевую направленность на покупку жилья, которое, в свою очередь, поступает в залог как гарантия возврата средств. Также возможен вариант, когда залогом может выступать другая недвижимость, которая уже находится в собственности у заемщика.

Условия по ипотечному кредиту с одной стороны более лояльные, чем по другим видам кредита, а с другой стороны - более требовательные. $\mathrm{K}$ более лояльным условиям ипотечного кредита можно отнести более низкую процентную ставку, чем по другим банковским продуктам. Данное условие вполне очевидное и разумное, т.к. залогом выступает недвижимость - очень надежный и ценный актив с соответствующим уровнем ликвидности.

K более требовательным условиям ипотечного кредита нужно отнести необходимость подтверждения дохода и стажа работы соответствующими справками и документами, более того банки сами устанавливают минимальные общий стаж работы и минимальный стаж работы на последнем месте работы для получения ипотечного кредита у них банке. Также банк сам определяет какую долю от заработной платы заемщик в состоянии ежемесячно тратить на погашение ипотеки, большинство банков определяют эту сумму на уровне не выше 50\% от общей величины личного (семейного) дохода. При этом не стоит забывать про требование ипотечного страхования и внесение первоначального взноса, обычно, на уровне $10-15 \%$ от стоимости жилья.

В связи с тем, что ипотечное кредитование очень распространенный и популярный способ покупки недвижимости для собственного проживания, а также в некоторых случаях для некоторых людей способ инвестирования свободных средств, автор видит достаточно актуальным вопросом анализ экономической эффективности ипотечного кредита.

Экономическая эффективность ипотечного кредита будет оценена следующим способом:

Заемщик, который хочет жить самостоятельно в отдельном жилье может купить квартиру в ипотеку либо снимать жилье. В случае ипотечного кредита заемщик вносит первоначальный взнос в размере $\mathrm{X}$ руб. и уплачивает каждый месяц аннуитетный платеж, т.к. это наиболее приемлемый вариант для большинства заемщиков, т.к. позволяет уплачивать равномерную сумму на протяжении всего срока возврата средств. В случае аренды квартиры уплачивается ежеме- 
сячная арендная плата. Если аннуитетный платеж по ипотечному кредиту больше величины арендной платы, то у заемщика теоретически оставалось бы некоторая сумма, которую можно инвестировать. Также можно инвестировать первоначальный взнос, который теоретически должен был быть у потенциального заемщика и в случае выбора аренды квартира остался неиспользованным. Предположим, что у заемщика отсутствуют какие-либо экономические знания приемлемого уровня, в связи с чем данные средства предполагается инвестировать наименее рискованным способом - в облигации федерального займа (ОФЗ), наиболее надежный вид вложений. Через срок n лет уплаты аннуитетного ипотечного платежа заемщик будет иметь в собственности недвижимость стоимостью, равной сумме тела кредита и величине первоначального взноса. Через срок $\mathrm{n}$ лет уплаты арендной платы и инвестирования оставшейся части ежемесячного платежа и первоначального взноса в ОФЗ заемщик имел бы наращенную сумму данного капитала. Если сумма наращенного капитала больше величины стоимости квартиры, то ипотечный кредит экономически неэффективен.

Для проведения оценки экономической эффективности ипотечного кредита возьмем следующие входящие условия:

1) Проводим оценку экономической эффективности для Московского региона;

2) Рассматриваем ипотечный кредит для приобретения квартиры в новостройке, т.к. данная покупка является наименее рисковой и наименее сложной с точки зрения оформления сделки (в случае вторичного жилья могут быть юридически сложные случаи признания сделки недействительной с самыми разнообразными последствиями);

3) Оценка экономической эффективности проводится для однокомнатной, двухкомнатной и трехкомнатной квартир, т.к. это наиболее популярные, массовые и распространенные варианты для приобретения;

4) При оценке экономической эффективности предполагается, что если заёмщик берет ипотечный кредит на квартиру в конкретном районе, то он также хочет/будет и снимать квартиру именно в этом районе с таким же количеством комнат.

5) Для проведения анализа выбрана выборка из 5-ти однокомнатных, 5-ти двухкомнатных и 5-ти трехкомнатных квартир на Юге,
Севере и Западе Москвы. Итого получилась выборка из 45 квартир для аренды и 45 квартир для приобретения. Выборка проведена с помощью интернет-агрегатора ЦИАН на 15.10.2021. [1]

6) Предполагаем, что при анализе стоимость жилья для покупки в конкретном районе выбрана наиболее минимальная из имеющегося предложения. То есть в конкретном районе более дешевого варианта приобретения квартиры нет. Также предполагается, что при анализе арендная плата за квартиру выбрана на уровне выше среднего по конкретному району. То есть в данном районе есть более дешевые варианты аренды квартиры, но предполагается, что заемщик хочет проживать в квартиры с хорошим ремонтом и условиями.

7) Для проведения анализа экономической эффективности выбрана совокупность 10 крупных банков из ТОП30 банков, работающих в Московском регионе по направлению ипотечное кредитование. Из данных банков в качестве ипотечной ставки выбран банк с наилучшими условиями для заемщика - РОСБАНК, процентная ставка $7,4 \%$, а первоначальный взнос $10 \%$ от стоимости покупки на 15.10.2021. [2] То есть другие банки выдает ипотеку с более невыгодными условиями в отношении процентной ставки и первоначального взноса. [3]

8) Для проведения анализа экономической эффективности выбран наименее рискованный актив - облигации федерального займа с доходность 7\%. На рынке присутствуют более доходные и также надежные корпоративные облигации крупнейший компаний Российской Федерации с доходность 8-9\%. [4]

9) Для проведения анализа экономической эффективности выбран подход наибольшего благоприятствования для выбора ипотечного кредитования и отказа от аренды. То есть при анализе ипотечного кредитования принимаются в расчет квартиры по неменьшей стоимости, ипотечное кредитование с наименьшей ставкой и первоначальным взносом, а для аренды квартиры принимаются в расчет средние аридные ставки и наименьшая процентная ставка дохода от инвестирования средств. То есть в случае теоретического доказательства при данных условиях, что ипотечное кредитование экономически неэффективно, то в действительности экономическая неэффективность будет еще больше, т.к. квартиру можно арендовать более дешево, средства вложить более выгодно, а при этом в 
приобретенном жилье нужно еще сделать и поддерживать ремонт, уплачивать коммунальные платежи и проч.

Для проведения оценки экономической эффективности ипотечного кредита будет использован следующий математический аппарат:

1) Для расчета ежемесячного ипотечного платежа будет использована $p$-срочная рента постнумерандо, когда годовой рентный платеж $R$ разбит на $p$ одинаковых платежей, равномерно распределенных в течение года. Тело ипотечного кредита $A(p)$ равно приведенной величине $p$-срочной ренты поснумерандо. Всего за $n$ лет производится $n p$ платежей по $R / p$ каждый.

2) Расчет суммы накопленного капитала путем инвестирования разницы между величиной ипотечного платежа $R / p$ и величиной арендной платы $Y / p$ производится через расчет наращенной величины $p$-срочной ренты. За $n$ лет производится также $n p$ платежей по $(R / p-Y / p)$. Далее к данной величине добавляется величина первоначального взноса $X$, также увеличившаяся со временем $n$ по правилу сложного процента.

Начнем с расчета ежемесячного ипотечного платежа по представленной выборке квартир. В качестве срока $n$ возьмем 20 лет, т.к. данный срок наиболее часто используется банками в качестве срока возврата ипотечного кредита.

Тело кредита (приведенная величина $p$-сроч- ной ренты постнумерандо) представляет собой сумму геометрической прогрессии

$$
\begin{aligned}
& A^{(p)}=\frac{R}{p(1+i)^{\frac{1}{p}}}+\frac{R}{p(1+i)^{\frac{2}{p}}}+\cdots+\frac{R}{p(1+i)^{\frac{n p}{p}}} \\
& \text { где } a_{1}=R / p \text { и } q=\frac{1}{(1+i)^{\frac{1}{p}}} \cdot[5]
\end{aligned}
$$

Путем несложных преобразований автор приходит к уравнению вида

$$
A^{(p)}=\frac{R}{p} \times \frac{\left(1-(1+i)^{-n}\right)}{\left((1+i)^{\frac{1}{p}}-1\right)},
$$

выражая отсюда величину годового ипотечного платежа получаем

$$
R=A^{(p)} \times p \times \frac{\left((1+i)^{\frac{1}{p}}-1\right)}{\left(1-(1+i)^{-n}\right)}
$$

где $A(p)$ - тело кредита, $i$ - ставка процента по кредиту, $p$ - количество месяцев в году, $n-$ количество лет, в течение которого погашается кредит, $R$ - величина годового ипотечного платежа.

С помощью простых расчетов определяем ве-

\begin{tabular}{|c|c|c|c|c|c|}
\hline \multicolumn{2}{|c|}{ Жилье в районе Юга Москвы } & \multicolumn{2}{|c|}{ Жилье в районе Севера Москвы } & \multicolumn{2}{|c|}{ Жилье в районе Запада Москвы } \\
\hline Квартира № & $\begin{array}{c}\text { Годовой платеж } \\
\text { по ипотечному } \\
\text { кредиту, млн. } \\
\text { руб. }\end{array}$ & Квартира № & $\begin{array}{c}\text { Годовой платеж } \\
\text { по ипотечному } \\
\text { кредиту, млн. } \\
\text { руб. }\end{array}$ & Квартира № & $\begin{array}{c}\text { Годовой платеж } \\
\text { по ипотечному } \\
\text { кредиту, млн. } \\
\text { руб. }\end{array}$ \\
\hline 1 & 0,86 & 1 & 0,87 & 1 & 1,28 \\
\hline 2 & 0,72 & 2 & 1,02 & 2 & 0,86 \\
\hline 3 & 0,68 & 3 & 0,73 & 3 & 0,86 \\
\hline 4 & 0,71 & 4 & 0,79 & 4 & 1,20 \\
\hline 5 & 0,75 & 5 & 0,73 & 5 & 1,89 \\
\hline 6 & 1,09 & 6 & 1,48 & 6 & 1,70 \\
\hline 7 & 0,89 & 7 & 1,41 & 7 & 1,43 \\
\hline 8 & 0,88 & 8 & 1,18 & 8 & 1,26 \\
\hline 9 & 0,92 & 9 & 0,96 & 9 & 1,70 \\
\hline 10 & 0,99 & 10 & 0,97 & 10 & 1,74 \\
\hline 11 & 1,39 & 11 & 1,81 & 11 & 1,99 \\
\hline 12 & 1,10 & 12 & 1,69 & 12 & 2,10 \\
\hline 13 & 1,13 & 13 & 1,40 & 13 & 1,53 \\
\hline 14 & 1,15 & 14 & 1,22 & 14 & 2,24 \\
\hline 15 & 1,17 & 15 & 1,20 & 15 & 4,03 \\
\hline
\end{tabular}
личину годового платежа по ипотеке для всей выборки квартир в разных районах Москвы (табл. 1).

Таблица 1. Величина годового ипотечного платежа по всей выборке квартир 
Далее переходим к расчету в отношении накопленного капитала путем инвестирования первоначального взноса и разницы между ипотечным платежом и арендной платой. Так, произведем расчет суммы разницы между величиной ипотечного платежа $R / p$ и величиной арендной платы $Y / p$ за один год

$$
\left(\frac{R}{p}-\frac{Y}{p}\right) \times p=R-Y
$$

где $Y$ - сумма арендной платы за один год, $R$ - величина годового ипотечного платежа (табл. 2).

Теперь же можно произвести расчет суммы накопленного капитала. Величина накопленного капитала (наращенная величина р-срочной ренты постнумерандо суммированная с наращенным первоначальным взносом по правилу сложного процента) представляет собой сумму геометрической прогрессии и сумму наращенного первоначального взноса

$$
\begin{aligned}
& S^{(p)}+X^{n}=\frac{(R-Y)}{p}+\frac{(R-Y)}{p} \times(1+c)^{\frac{1}{p}}+\cdots \\
& +\frac{(R-Y)}{p} \times(1+c)^{\frac{n p}{p}}+X \times(1+c)^{n}
\end{aligned}
$$$$
\text { где } a_{1}=(R-Y) / p \text { и } \quad q=(1+c)^{1 / p} \quad \text {. [5] }
$$

Путем несложных преобразований автор приходит к уравнению вида

$S^{(p)}+X^{n}=\frac{(R-Y)}{p} \times \frac{\left((1+c)^{n}-1\right)}{\left((1+c)^{\frac{1}{p}}-1\right)}+X \times(1+c)^{n}$

где $(R-Y)$ - величина годовой разницы между ипотечным платежом и арендной платой, $c-$ ставка процента по ОФЗ, $p$ - количество месяцев в году, $X-$ величина первоначального взноса по кредиту, которая была бы по кредиту, $n-$ количество лет, в течение которых погашался бы кредит. Данное уравнение показывает величину накопленного капитала.

C помощью простых расчетов определяем величину накопленного капитала для всей выборки квартир в разных районах Москвы (табл. 3).

После проведенных расчетов остается только сравнить величину накопленного капитала со стоимостью квартиры (табл. 4).

Из представленной таблицы 4 видно, что абсолютно для каждого члена выборки величина накопленного капитала превышает стоимость жилья минимум в 1,5 раза, а средняя величина превышения по выборке в 2,12 раза. То есть в среднем стоимость жилья за 20 лет должна уве-

\section{Таблица 2. Величина годовой разницы между ипотечным платежом и арендной платой}

\begin{tabular}{|c|c|c|c|c|c|}
\hline \multicolumn{2}{|c|}{ Жилье в районе Юга Москвы } & \multicolumn{2}{|c|}{ Жилье в районе Севера Москвы } & \multicolumn{2}{|c|}{ Жилье в районе Запада Москвы } \\
\hline Квартира № & $\begin{array}{c}\text { Величина го- } \\
\text { довой разницы } \\
\text { между ипоте- } \\
\text { ным платежом } \\
\text { и арендной } \\
\text { платой, млн. руб. }\end{array}$ & $\begin{array}{c}\text { Величина го- } \\
\text { довой разницы } \\
\text { между ипоте- } \\
\text { ным платежом } \\
\text { и арендной } \\
\text { платой, млн. руб. }\end{array}$ & Квартира № & $\begin{array}{c}\text { довой разницы } \\
\text { между ипотеч- } \\
\text { ным платежом } \\
\text { и арендной } \\
\text { платой, млн. руб. }\end{array}$ \\
\hline 1 & 0,44 & 1 & 0,38 & 1 & 0,78 \\
\hline 2 & 0,36 & 2 & 0,59 & 2 & 0,36 \\
\hline 3 & 0,35 & 3 & 0,35 & 3 & 0,50 \\
\hline 4 & 0,26 & 4 & 0,40 & 4 & 0,62 \\
\hline 5 & 0,33 & 5 & 0,33 & 5 & 0,99 \\
\hline 6 & 0,55 & 6 & 0,91 & 6 & 0,98 \\
\hline 7 & 0,37 & 7 & 0,77 & 7 & 0,71 \\
\hline 8 & 0,34 & 8 & 0,52 & 8 & 0,66 \\
\hline 9 & 0,34 & 9 & 0,42 & 9 & 0,82 \\
\hline 10 & 0,45 & 10 & 0,43 & 10 & 0,54 \\
\hline 11 & 0,77 & 11 & 1,13 & 11 & 0,97 \\
\hline 12 & 0,44 & 12 & 0,97 & 12 & 1,14 \\
\hline 13 & 0,47 & 13 & 0,64 & 13 & 0,81 \\
\hline 14 & 0,46 & 14 & 0,50 & 14 & 1,21 \\
\hline 15 & 0,46 & 15 & 0,54 & 15 & 2,11 \\
\hline
\end{tabular}


Таблица 3. Итоговая сумма накопленного капитала

\begin{tabular}{|c|c|c|c|c|c|}
\hline \multicolumn{2}{|c|}{ Жилье в районе Юга Москвы } & \multicolumn{2}{|c|}{ Жилье в районе Севера Москвы } & \multicolumn{2}{|c|}{ Жилье в районе Запада Москвы } \\
\hline Квартира № & $\begin{array}{c}\text { Итоговая сумма } \\
\text { накопленного } \\
\text { капитала, млн. } \\
\text { руб. }\end{array}$ & $\begin{array}{c}\text { Ктоговая сумма } \\
\text { накопленного } \\
\text { капитала, млн. } \\
\text { руб. }\end{array}$ & Квартира № & $\begin{array}{c}\text { наковая суммана } \\
\text { капитала, млн. } \\
\text { руб. }\end{array}$ \\
\hline 1 & 22,36 & 1 & 20,11 & 1 & 38,67 \\
\hline 2 & 18,54 & 2 & 29,40 & 2 & 19,20 \\
\hline 3 & 18,08 & 3 & 17,92 & 3 & 25,29 \\
\hline 4 & 14,08 & 4 & 20,70 & 4 & 31,65 \\
\hline 5 & 17,19 & 5 & 17,41 & 5 & 50,52 \\
\hline 6 & 28,01 & 6 & 45,16 & 6 & 49,00 \\
\hline 7 & 19,89 & 7 & 39,04 & 7 & 36,68 \\
\hline 8 & 18,47 & 8 & 27,30 & 8 & 33,81 \\
\hline 9 & 18,54 & 9 & 22,05 & 9 & 42,40 \\
\hline 10 & 23,64 & 10 & 22,45 & 10 & 30,68 \\
\hline 11 & 38,76 & 11 & 56,08 & 11 & 50,21 \\
\hline 12 & 23,73 & 12 & 48,60 & 12 & 57,91 \\
\hline 13 & 24,92 & 13 & 33,57 & 13 & 41,05 \\
\hline 14 & 24,59 & 14 & 26,75 & 14 & 61,23 \\
\hline 15 & 24,88 & 15 & 28,10 & 15 & 107,49 \\
\hline
\end{tabular}

\section{Таблица 4. Сравнение суммы накопленного капитала со стоимостью квартиры}

\begin{tabular}{|c|c|c|c|c|c|}
\hline \multicolumn{2}{|c|}{ Жилье в районе Юга Москвы } & \multicolumn{2}{|c|}{ Жилье в районе Севера Москвы } & \multicolumn{2}{|c|}{ Жилье в районе Запада Москвы } \\
\hline Квартира № & $\begin{array}{c}\text { Во сколько } \\
\text { раз величина } \\
\text { накопленного } \\
\text { капитала выше } \\
\text { стоимости } \\
\text { жилья }\end{array}$ & $\begin{array}{c}\text { Во сколько } \\
\text { раз величина } \\
\text { накопленного } \\
\text { капитала выше } \\
\text { стоимости } \\
\text { жилья }\end{array}$ & $\begin{array}{c}\text { Коз сколько } \\
\text { накопленного } \\
\text { капитала выше } \\
\text { стоимости } \\
\text { жилья }\end{array}$ \\
\hline 1 & 2,21 & 1 & 1,95 & 1 & 2,56 \\
\hline 2 & 2,18 & 2 & 2,45 & 2 & 1,88 \\
\hline 3 & 2,26 & 3 & 2,08 & 3 & 2,48 \\
\hline 4 & 1,68 & 4 & 2,23 & 4 & 2,24 \\
\hline 5 & 1,95 & 5 & 2,02 & 5 & 2,27 \\
\hline 6 & 2,19 & 6 & 2,58 & 6 & 2,45 \\
\hline 7 & 1,89 & 7 & 2,35 & 7 & 2,17 \\
\hline 8 & 1,78 & 8 & 1,96 & 8 & 2,27 \\
\hline 9 & 1,72 & 9 & 1,95 & 9 & 2,12 \\
\hline 10 & 2,02 & 10 & 1,97 & 10 & 1,50 \\
\hline 11 & 2,36 & 11 & 2,62 & 11 & 2,14 \\
\hline 12 & 1,83 & 12 & 2,44 & 12 & 2,34 \\
\hline 13 & 1,87 & 13 & 2,03 & 13 & 2,28 \\
\hline 14 & 1,81 & 14 & 1,86 & 14 & 2,32 \\
\hline 15 & 1,80 & 15 & 1,99 & 15 & 2,26 \\
\hline
\end{tabular}


личиться в 2,12 раза, чтобы хотя бы быть на одном уровне с величиной накопленного капитала.

Автором был проведен анализ экономической эффективности ипотечного кредита для приобретения квартиры в новостройке в Москве. Анализ был построен на базе сравнения экономической эффективности покупки собственного жилья за счет ипотечного кредита, когда в конце срока выплаты кредита квартира оказывается в собственности у заемщика, и аренды жилья уровнем выше среднего в том же районе при инвестировании в ОФЗ разницы между суммой ежемесячного платежа по ипотечному кредиту и арендной платой за съемное жилье за месяц, а также при инвестировании в ОФЗ первоначального взноса, который должен был быть уплачен при ипотечном кредите.

В результате проведенного анализа на базе совокупности из 45 членов в разных частях Москвы было выявлено, что в среднем величина накопленного капитала при аренде жилья и инвестировании разницы между ипотечным платежом и арендным платежом в 2,12 раза больше, чем стоимость жилья, приобретаемого при ипотечном кредите. То есть, чтобы жилье через 20 лет было хотя бы на одном уровне с величиной накопленного капитала оно должно стабильно от года к году расти в цене на $3,8-4,0 \%$. При этом прогнозы большинства аналитиков прогнозируют рост на уровне $1,5-2 \%$ в год, что соответствует итоговому повышению через 20 лет лишь на 35-49\%.

При это стоит учитывать также такие материальные вложения в собственную квартиру как ремонт, который необходимо обновлять хотя бы раз в 15 лет, чтобы соответствовать комфорту как в съемной квартире ценового диапазона выше среднего, а также уплату ежемесячной коммунальной платы. Данные два фактора являются дополнительным фактором удорожания собственного жилья, то есть в действительности величина накопленного капитала будет еще выше, а ипотечный кредит еще менее выгодным.

В данной статье автором была рассмотрена исключительно экономическая составляющая выбора между собственным жильем и арендой жилья. Понятно, что при выборе у заемщика также присутствуют «поведенческие» факторы принятия решения и каждый волен сам решать, какой вариант для него будет наиболее предпочтительным. Однако, на основании проведенных расчетов автор может прийти к выводу, что исключительно экономически более целесообразно снимать жилье и инвестировать разницу между ипотечным платежом и арендной платой как минимум в ОФЗ, а как максимум, при наличии соответствующих знаний, в другие инструменты финансового рынка.

\section{Библиографический список}

1. Интернет-ресурс сайт ЦИАН, раздел «купить/снять квартиры», доступ по ссылке - URL: https://www.cian. $\mathrm{ru}$ / (дата обращения 15.10.2021)

2. Интернет-ресурс сайт РОСБАНК, раздел «ипотека», доступ по ссылке - URL: https://www.rosbank.ru/ipoteka/ novostrojka/ (дата обращения 15.10.2021)

3. Интернет-ресурс сайт Банки.ру, раздел «ипотека», доступ по ссылке - URL: https://www.banki.ru/products/ hypothec/?source=main_menu_hypothec \&page=2 (дата обращения 15.10.2021)

4. Интернет-ресурс сайт SMART-LAB, раздел «облигации», доступ по ссылке - URL: https://smart-lab.ru/bonds/ (дата обращения 15.10.2021)

5. Брусов, П.Н., Филатова, Т.В., Орехова, Н.П., Брусов, П.П. Финансовая математика [Текст] / Брусов, П. Н., Филатова, Т. В., Орехова, Н. П., Брусов, П. П.- М.: КНОРУС, 2015.-152с. 